\title{
Biliary Complications in Living Donor Liver Transplantation: Imaging Findings and the Roles of Interventional Procedures
}

\author{
Jung Min Chang, Jeong Min Lee, Kyung Suk Suh, Nam Joon Yi, Yong Tae Kim, \\ Se Hyung Kim, Joon Koo Han, Byung Inn Choi
}

Department of Radiology and Institute of Radiation Medicine, Seoul National University College of Medicine, 28 Yongon-dong, Chongno-gu, Seoul 110-744, Korea

\section{Abstract}

Purpose: To describe the incidence, types, and findings of biliary complications in living donor liver transplantation (LDLT) and to determine the roles of interventional procedures.

Materials and methods: Twenty-four biliary complications among 161 LDLT patients (24/161, 14.9\%) were identified. These complications were divided into two groups according to the initial manifestation time, i.e., "early" ( $<60$ days) or "late". The CT and cholangiographic findings were reviewed regarding the presence of a stricture or leak and the location, and length, shape, and degree of the stricture. Both groups were categorized into three subgroups: leak, stricture, and both. The type of interventional procedures used and their roles were determined.

Results: Early complications were identified in 14 of the 24 patients (58\%) and late complications in 11 (46\%). One patient showed both early and late complications. Biliary stricture was detected in 10 patients, leak in 10 , and both in 5. By cholangiography, all strictures were irregular and short (mean length $15 \pm 6 \mathrm{~mm}$ ) at the anastomotic site and complete obstruction was observed in 2 patients with late stricture. Twenty-three of the 24 patients were treated using percutaneous and/or endoscopic drainage procedures with or without balloon dilatation. Seventeen (74\%) showed a good response, but reoperations were inevitable in $6(26 \%)$. All patients except those with complete obstruction showed a favorable outcome after interventional management.

Conclusion: Biliary leaks and strictures are predominant complications in LDLT. Most show good responses to interventional treatment. However, complete obstruction needs additional operative management.

Correspondence to: J. K. Han, M.D.; email: hanjk@radcom.snu.ac.kr
Key words: Biliary complications-Cholangiography, CT-Interventional procedure-Liver transplantation

Living donor liver transplantation (LDLT) is emerging as an alternative to cadaveric liver transplantation because of a growing demand for liver transplantation and the scarcity of cadaveric livers [1-3]. The surgical techniques and immunosuppressive therapies used for this procedure have improved considerably; nevertheless, there are still significant complications, including arterial and venous thrombosis, biliary leak and stricture, fluid collection, lymphoproliferative disorders, infection, and recurrent tumors [1-3]. Among these, biliary complications remain a troublesome clinical problem.

Nowadays, radiologic or endoscopic interventional approaches are available to define and treat these biliary complications with high success rates and much reduced invasiveness, and in many institutes interventional biliary procedures are increasingly used for the treatment of biliary complications in LDLT [4-6].

The purpose of this study was to describe the types of biliary complications in LDLT and their cholangiographic findings, and to determine the roles of the radiologic interventional procedures used to treat complications.

\section{Materials and Methods}

\section{Patients}

From January 1999 to February 2003, 161 patients underwent LDLT at our institution. Among them, 26 patients showed biliary complications (26/161). There were 20 men and 6 women, ranging in age from 5 to 69 years (mean $41.8 \pm 16.9$ years). Among these patients, 2 were excluded because no treatment was performed. Of the remaining 24 patients, left lobe LDLT was performed in 6 and right lobe LDLT in 18. Biliary reconstruction had been performed 
Table 1. Summary of location, types, management and outcomes of early biliary complications

\begin{tabular}{|c|c|c|c|c|c|c|c|c|c|c|}
\hline Patient no. & Sex & $\begin{array}{l}\text { Age } \\
\text { (years) }\end{array}$ & $\begin{array}{l}\text { Method } \\
\text { of } \\
\text { anastomosis }\end{array}$ & $\begin{array}{l}\text { Underlying } \\
\text { disease }\end{array}$ & Complication & Location & $\begin{array}{l}\text { Length of } \\
\text { stenotic } \\
\text { segment } \\
(\mathrm{mm})\end{array}$ & $\begin{array}{l}\text { Initial } \\
\text { manifestation } \\
\text { (days) }\end{array}$ & Management & $\begin{array}{l}\text { Intervention-free } \\
\text { follow-up interval } \\
\text { (months) }\end{array}$ \\
\hline 1 & $\mathrm{~F}$ & 48 & DD & $\mathrm{HCC}$ & Leak & AN & & 42 & PCD & 39 \\
\hline 2 & $\mathrm{~F}$ & 13 & $\mathrm{HJ}$ & BA & Leak & AN & & 10 & PCD, PTBD & 6 \\
\hline 3 & $\mathrm{~F}$ & 6 & HJ & BA & Leak & AN & & 7 & Reoperation & 52 \\
\hline 4 & $\mathrm{M}$ & 52 & HJ & $\mathrm{LC}$ & Leak & AN & & 55 & PCD & 59 \\
\hline 5 & M & 69 & DD & $\mathrm{HCC}$ & Leak & AN & & 16 & PCD & 13 \\
\hline 6 & M & 57 & DD & $\mathrm{LC}$ & Leak & multifocal & & 15 & PCD, PTBD & 6 \\
\hline 7 & M & 31 & DD & $\begin{array}{l}\text { Wilson's } \\
\text { disease }\end{array}$ & $\begin{array}{l}\text { Leak with } \\
\text { stricture }\end{array}$ & AN & 9 & 8 & $\begin{array}{l}\text { PCD, PTBD, ENBD } \\
\text { balloon dilatation (1) }\end{array}$ & 13 \\
\hline 8 & $\mathrm{~F}$ & 49 & DD & $\mathrm{HCC}$ & $\begin{array}{r}\text { Leak with } \\
\text { stricture }\end{array}$ & AN & 18 & 18 & $\begin{array}{l}\text { PCD, PTBD, ENBD } \\
\text { balloon dilatation (1) }\end{array}$ & 35 \\
\hline 9 & M & 57 & DD & $\mathrm{LC}$ & $\begin{array}{r}\text { Leak with } \\
\text { stricture }\end{array}$ & AN & 30 & 16 & PCD, PTBD & 8 \\
\hline 10 & M & 48 & DD & $\mathrm{HCC}$ & $\begin{array}{r}\text { Leak with } \\
\text { stricture }\end{array}$ & AN & 12 & 14 & PCD, PTBD, reoperation & 22 \\
\hline 11 & M & 49 & DD & $\mathrm{HCC}$ & $\begin{array}{r}\text { Leak with } \\
\text { stricture }\end{array}$ & AN & 22 & 11 & ERBD & 34 \\
\hline 12 & $\mathrm{M}$ & 54 & DD & $\mathrm{LC}$ & stricture & AN & 20 & 27 & PTBD, balloon dilatation (1) & 31 \\
\hline 13 & $\mathrm{M}$ & 38 & DD & $\mathrm{LC}$ & stricture & AN & 10 & 30 & PTBD, balloon dilatation (3) & 16 \\
\hline 14 & $\mathrm{M}$ & 7 & HJ & BA & stricture & AN & 20 & 25 & PTBD & 68 \\
\hline
\end{tabular}

DD, duct-to-duct; HJ, hepaticojejunal anastomosis; HCC, hepatocellular carcinoma; LC, liver cirrhosis; BA, biliary atresia; AN, anastomotic site; ( ), number of balloon dilatations; PTBD, percutaneous transhepatic biliary drainage; PCD, percutaneous drainage; ERBD, endoscopic retrograde biliary drainage; ENBD, endoscopic nasobiliary drainage

with choledococholedochostomy in 18 , and choledochoenteric anastomosis in 6 . The reasons for LDLT were liver cirrhosis $(n=13)$, hepatocellular carcinoma $(n=6)$, biliary atresia $(n=4)$, and Wilson's disease $(n=1)$. The mean interval from the initial manifestation of biliary complications to the latest follow-up by medical records was 30 months (range 8-68 months). Neither the approval of the institutional review board at our hospital nor informed patient consent was required for the review of medical records and images.

\section{Diagnosis of Biliary Complication}

After LDLT, recipients regularly underwent several laboratory tests, including liver function test, and Doppler ultrasound (US), according to the routine protocol of our hospital, and tests were added whenever clinically needed.

A diagnosis of biliary complications was made by an abnormal liver function test and the combined interpretation of the findings of US, CT, magnetic resonance cholangiography, and direct cholangiography, which included percutaneous transhepatic cholangiography, endoscopic retrograde cholangiopancreatography, and T-tube cholangiography. The diagnostic features included biliary dilatation or presence of biloma at abdominal CT, and bile leak or stricture on cholangiography.

\section{Medical Record Review and Image Analysis}

A medical record review was conducted by one author (C.J.M). Information obtained from the review included: age, gender, reason for transplantation, methods of biliary anastomosis, time interval from LDLT to the detection of biliary complication, and changes in clinical and laboratory findings (serum bilirubin and alkaline phosphatase levels) before and after intervention.

The cholangiographic, CT, and US findings were reviewed retrospectively by three experienced radiologists (H.J.K., L.J.M., and K.S.H.) in consensus. To evaluate the therapeutic response of complications to the interventional procedures, depending on the time of the initial manifestation of the complications after LDLT, the patients were divided arbitrarily into two groups: early $(<60$ days) or late. Furthermore, these two groups were categorized into three subgroups: leak, stricture, and both. Assessments were made of the locations, lengths, and shapes of leaks and strictures, the completeness of the stricture, and the numbers of leaks or stricture sites. The completeness of strictures was categorized as complete or incomplete. Complete stricture was defined when outflow of the biliary tree was not visible and the passage of a guidewire was impossible. If complication sites were multiple, each complication was counted as one case.

\section{Interventional Drainage Procedures}

Percutaneous transhepatic and endoscopic drainage procedures were used to treat biliary complications. No specific criteria were used to choose radiologic or endoscopic approaches. However, in our institute radiologic interventional procedures were used preferentially for the treatment of biliary complications because the interventional radiologist was able to perform both biliary drainage for biliary decompression and percutaneous drainage for peritoneal fluid collections at the same time. Percutaneous transhepatic cholangiography (PTC) and biliary drainage procedures were performed by two experienced radiologists (H.J.K., L.J.M.) in an angiography suite guided by both US and fluoroscopy.

For sedation and analgesia, midazolam (Bukwang Pharmaceuticals, Seoul, Korea) and fentanyl (Keukdong Pharmaceuticals, Seoul, Korea) or Demerol (Keukdong Pharmaceuticals, Seoul, Korea) were used when necessary. A 21-gauge Chiba needle (Cook, Bloomington, IN) was used for percutaneous cholangiography. After obtaining the cholangiogram, a 0.018-inch guidewire (Cook, Bloomington, IN) was inserted into the duct through the Chiba needle and then, using the standard guidewire technique as 

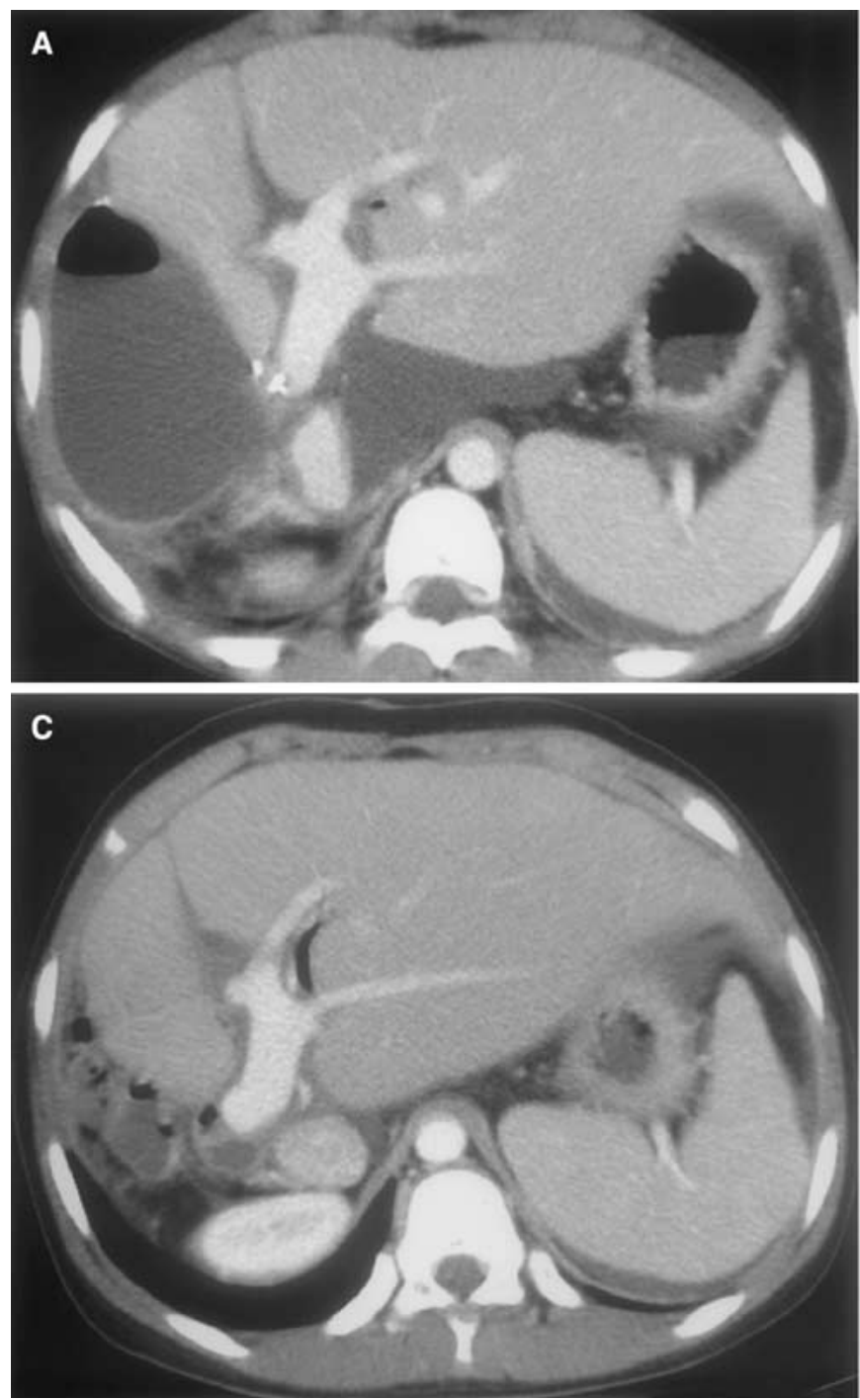

described elsewhere [7], a 5 Fr yellow sheath and a 0.035-inch Terumo guidewire were placed. When biliary stricture with or without a leak was detected by cholangiography, an attempt to pass the guidewire across the stricture was made.

For the treatment of biliary strictures passage of the guidewire through the stricture site was mandatory. After passage of the guidewire balloon dilatations were performed with $6-10 \mathrm{~mm}$ diameter balloons (Blue Max, Boston Scientific, Natick, MA) using the percutaneous transhepatic biliary drainage tract [7]. Finally an 8.5 Fr biliary drainage catheter (Cook, Bloomington, IL) was inserted in the bile duct. Follow-up cholangiography was obtained at 1-2 month intervals. If the stricture was resolved by subsequent cholangiography and hyperbilirubinemia was resolved, the catheter was locked and pulled above the stricture for 3 days. In the absence of fever, pain, or an elevated serum bilirubin level with the catheter locked, the catheter was removed. When stricture recurrence was demonstrated on follow-up CT or cholangiography, the procedure was repeated.

Endoscopic retrograde cholangiopancreatography (ERCP) was performed by an experienced endoscopist in the conventional manner. Sphincterotomy, endoscopic retrograde biliary drainage (ERBD) or endoscopic nasobiliary drainage (ENBD) was performed to divert biliary drainage.

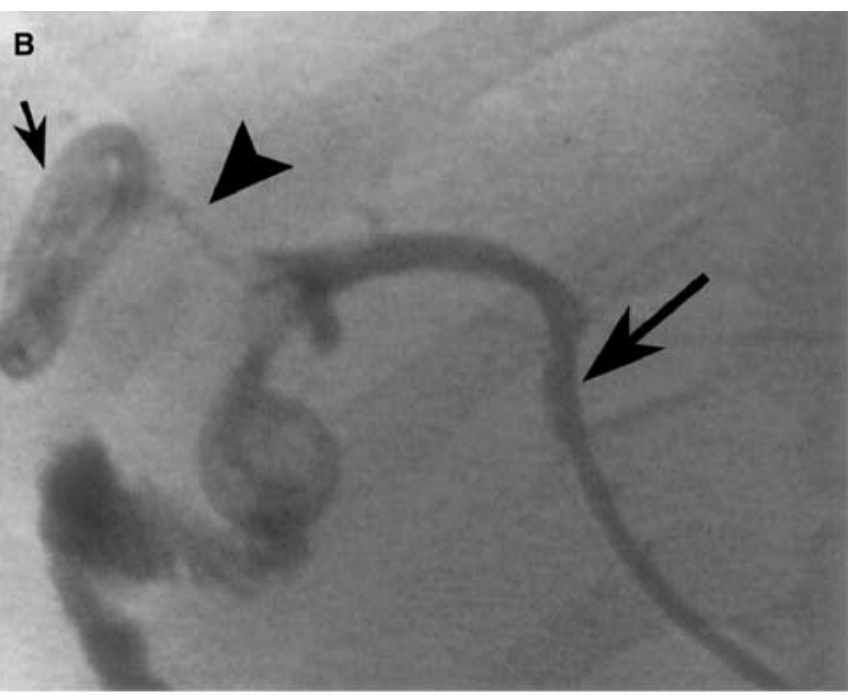

Fig. 1. A-C A 13-year-old boy who received left lobe LDLT. A Contrast-enhanced abdominal CT scan obtained 10 days after liver transplantation reveals a fluid collection at the edge of the anastomotic site. B Cholangiogram obtained through a percutaneous transhepatic biliary drainage catheter shows that PCD (small arrow) and PTBD catheters (large arrow) were placed; a biliary leak is shown (arrowhead). C Follow-up contrast-enhanced abdominal CT scan (after 6 months) shows resolution of the leak.

\section{Evaluation of Therapeutic Response}

Successful treatment of the biliary complications was defined as follows: (1) complete resolution of clinical symptoms, (2) no ongoing treatment and no necessity for additional surgical procedures related to biliary complications. When the interventional procedures successfully relieved biliary obstruction or peribiliary fluid collection, they were considered to have been curative, and when they failed to divert external drainage to internal drainage and reoperation was needed for internal drainage, the interventional procedure was considered to have been palliative.

We also evaluated whether procedure-related complications occurred, and documented how these complications were treated.

\section{Results}

\section{Early Complications}

Fourteen early complications $(14 / 24,58 \%)$ were identified $21 \pm 14.1$ days $($ mean \pm SD) after LDLT (Table 1$)$. The types of early complications were biliary leak $(6 / 24,25 \%)$, leak with stricture $(5 / 24,21 \%)$, and stricture alone $(3 / 24$, $13 \%)$. 

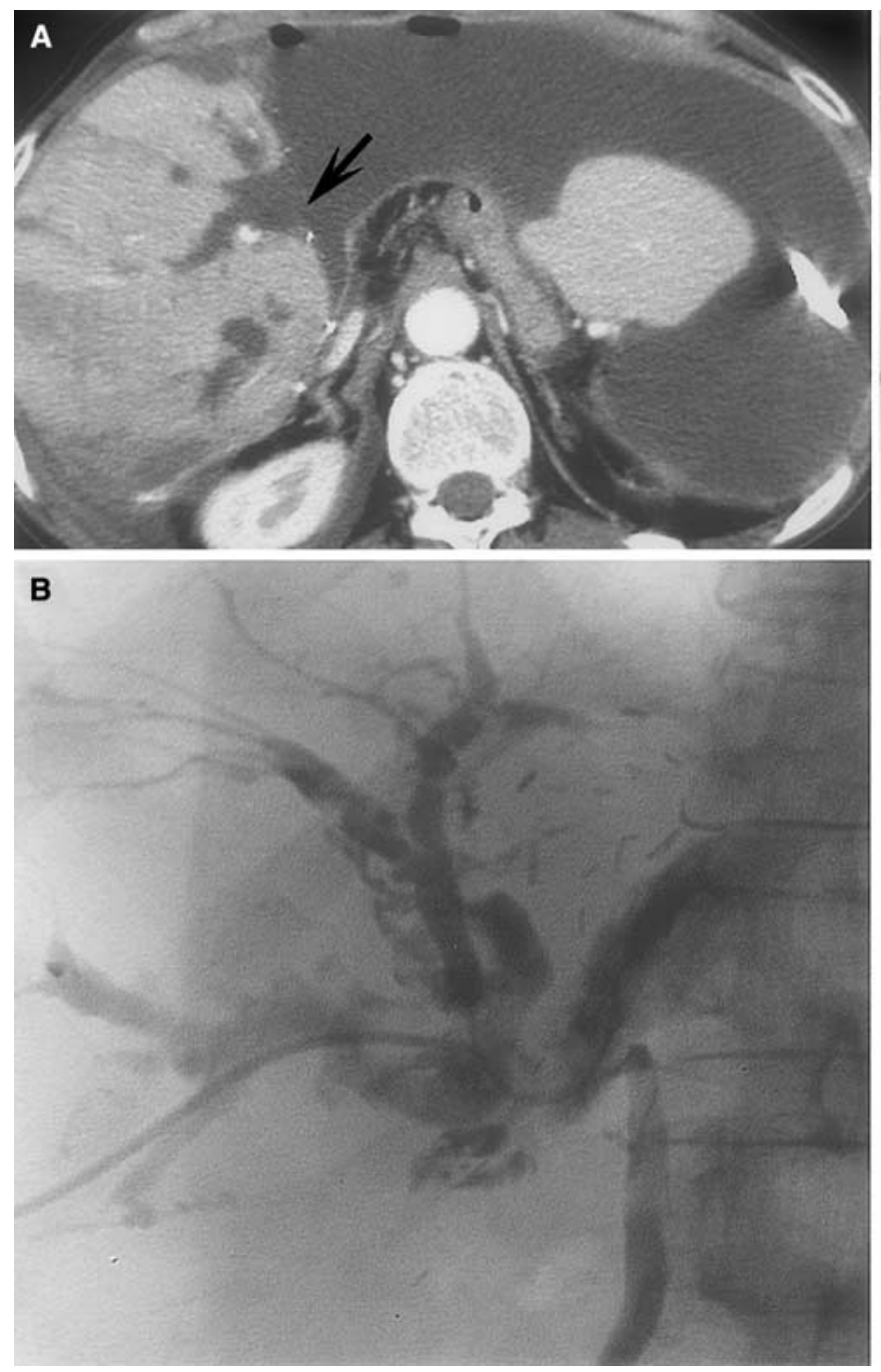

Six biliary leaks were observed as early as 7 days and as late as 55 days postoperatively (mean $24 \pm 20$ days). Mean follow-up period was 29.2 months (6-59 months). On US and/or CT, fluid collection was detected near the resection margin of the transplanted liver. In 5 of the 6 patients with a bile leak, percutaneous catheter drainage (PCD) was performed and in 2 additional percutaneous transhepatic biliary drainage (PTBD) was done. In one pediatric patient, reoperation was done because of bile peritonitis. Mean catheter dwelling period was 78 days (range 30-120 days). In these patients, a biliary leak was confirmed by inflow of contrast into the biliary duct on a sinogram through the PCD tube, or by the demonstration of a small dehiscence at the anastomotic site at operation. Five bile leaks occurred at the anastomotic site along the edge of the transplanted liver (Fig. 1). In one patient, a bile leak was caused by ischemic necrosis of the bile duct (Fig. 2). With the exception of one patient who showed ischemic necrosis of the bile duct, laboratory findings were normalized and follow-up CT showed decreased bile leak and no additional procedure was needed.

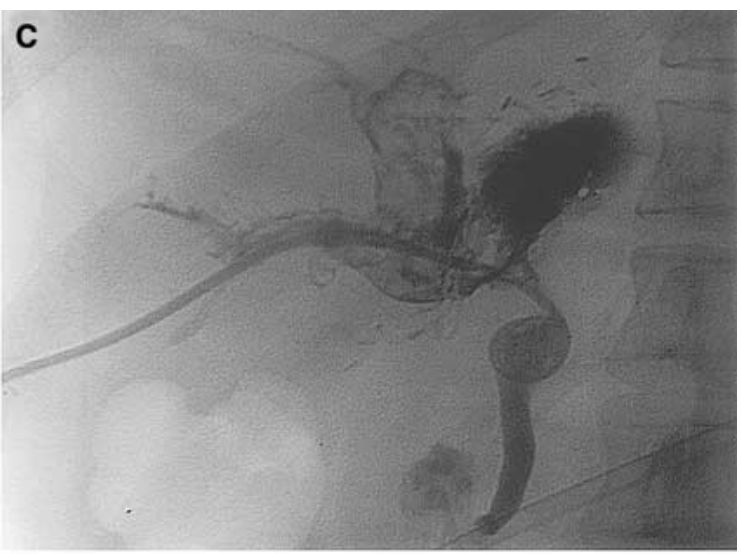

Fig. 2. A-C A 57-year-old man who underwent a right lobe LDLT. A Contrast-enhanced CT scan through the liver shows intrahepatic bile duct dilatations with peribiliary bile lakes (arrow). Note the large fluid collection adjacent to the resection margin. B, C Cholangiograms show multiple bile duct dilatations due to bile duct ischemia.

Five biliary leaks with strictures were observed between postoperative days 8 and 18 (mean \pm SD $13 \pm 4$ days). Mean follow-up period was 19.5 months (range 13-22 months). By direct cholangiography irregular, short segmental strictures $(17 \pm 9 \mathrm{~mm})$ were seen at the anastomotic site, accompanied by contrast leakage near the strictures (Fig. 3). In one case, ERBD was the only management. In the other 4 patients, PCD with PTBD with or without ENBD was performed. In 2 of these 4 patients balloon dilatations were performed (mean repetition time, $n=1$ ), and produced stricture improvement. Mean catheter dwelling period was 230 days (range 50-360 days). Revision operation was done in 1 of these 4 patients, because the stricture was not corrected by balloon dilatation. Severe fibrosis around the anastomotic site was confirmed by pathologic diagnosis.

Biliary strictures were observed in 3 patients between days 25 and 30 (28 \pm 2 days). Mean follow-up period was 38.3 months (range 31-68 months). PTBD was done in all cases. By cholangiography through the PTBD tube, strictures were identified in the anastomotic site (mean length $15 \pm 6 \mathrm{~mm}$,) and proximal bile ductal dilations were also 

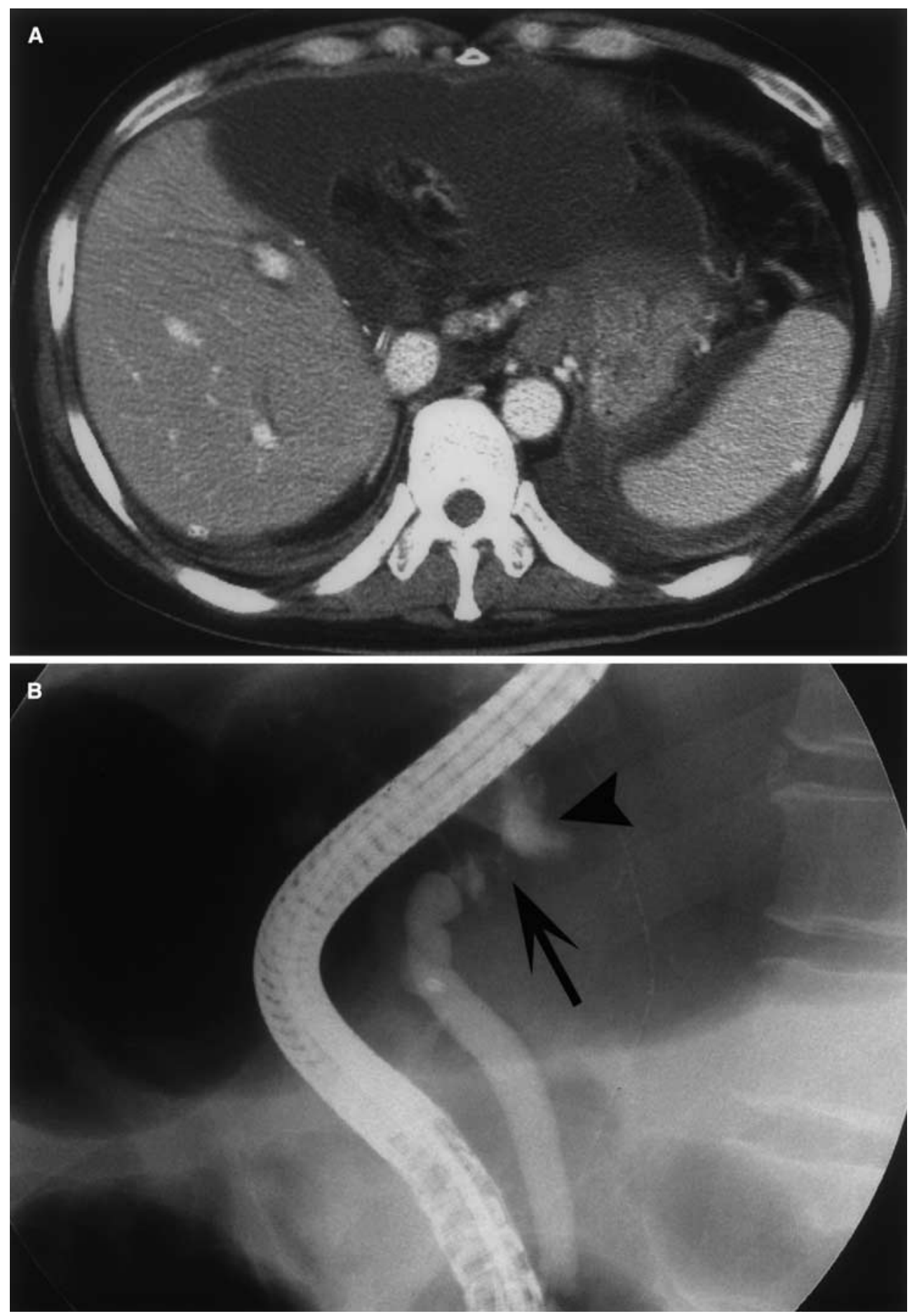

Fig. 3. A,B. A 48-year-old man with a right lobe LDLT. A Contrast-enhanced abdominal CT scan obtained 14 days after the operation shows a large fluid collection near the transplanted liver as well as mild dilation of the intrahepatic bile duct. B ERCP showing a stricture at the anastomotic site (arrow) and a leak (arrowhead) just above the stenotic portion. In this case a revision operation was done and these complications were found to be due to fibrosis.

identified. Biliary strictures were irregular in shape and all of the incomplete type. Balloon dilatation was successfully performed in 2 cases (Fig. 4) (mean repetition time, $n=2$ ). In the remaining patient additional balloon dilatation was not performed because of the small size of the duct. Mean catheter dwelling period was 250 days (range 60-450 days). Bile duct dilatation and an increased liver enzyme level were gradually decreased in all 3 patients after PTBD and/or balloon dilatation.

\section{Late Complications}

Thirteen late complications $(13 / 24,50 \%)$ were identified and occurred $177 \pm 70$ days after LDLT (Table 2). Late biliary complications were categorized into two groups: biliary stricture $(7 / 24,29 \%)$ and leakage $(4 / 24,17 \%)$. All late biliary leaks were associated with T-tube removal and not strictures, while there were 5 biliary leaks combined with stricture among the early complications. 

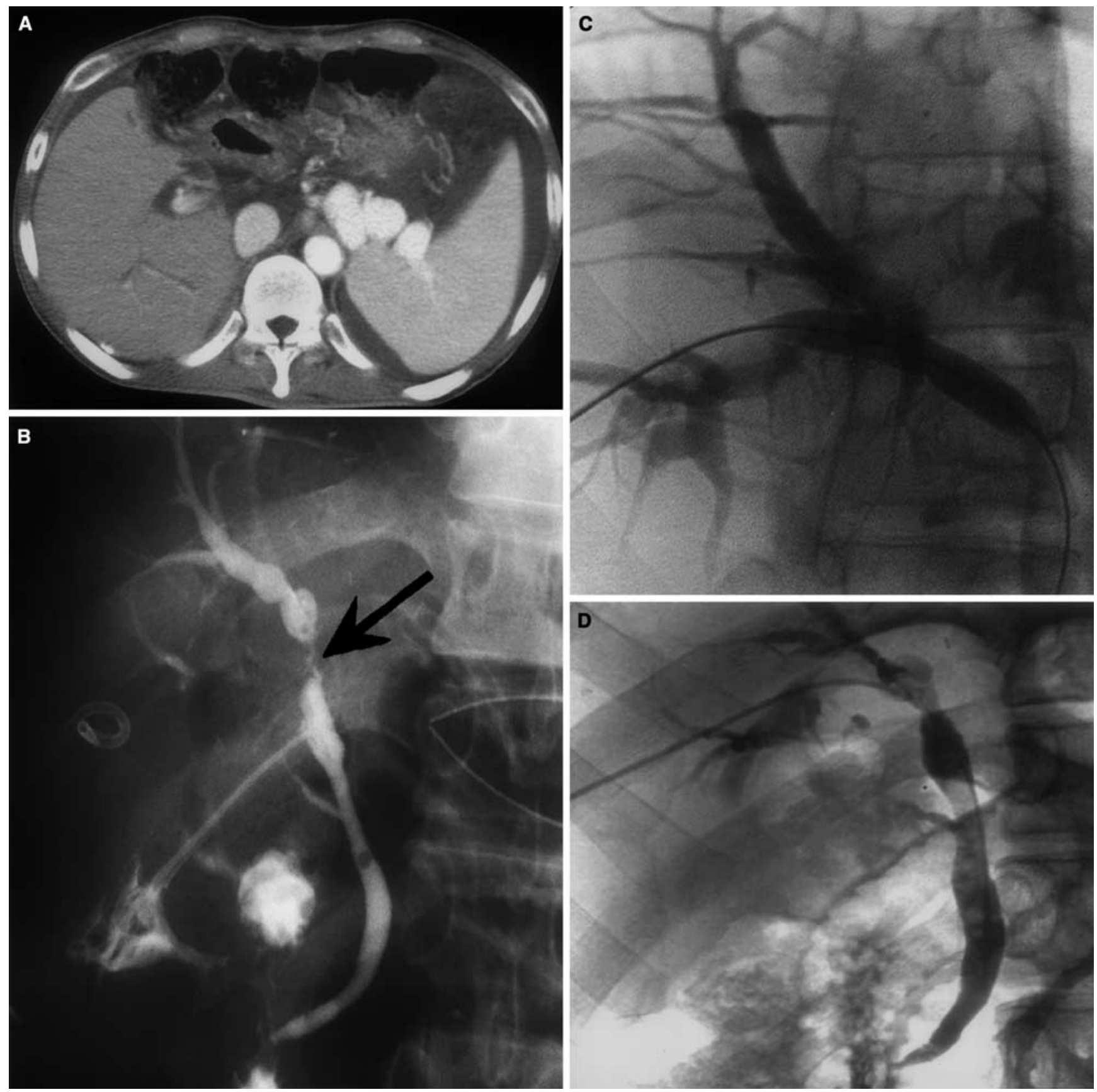

Fig. 4. A-D A 38-year-old male with right lobe LRLT who developed biliary stenosis. A Contrast-enhanced CT scan obtained 30 days after the operation, shows intrahepatic duct dilatation and intraperitoneal fluid collection. B T-tube cholangiography revealed an anastomotic site stricture (ar-

Seven late biliary strictures were identified 62-716 days after the surgery, and were located at the anastomotic site (237 \pm 176 days). Mean follow-up period was 37.6 months (range 31-56 months). By cholangiography, the strictures were irregularly shaped and their mean length was $13 \pm 6$ $\mathrm{mm}$. There were 2 complete biliary obstructions $(39 \%, 2 / 7)$ row). C Cholangiogram obtained after guidewire placement through a bile duct. Repeated balloon dilatation was performed. D After balloon dilatation, this cholangiogram shows a marked improvement in luminal patency.

without contrast passage in the downstream ducts (Fig. 5). All late biliary strictures were initially treated with PTBD, and then balloon dilation (mean repetition time, $n=2$ ) was performed in 4 patients and a revision operation in the other 3 cases. One of the 4 patients treated by PTBD and balloon dilation did not show a good response to the interventional 
Table 2. Summary of location, types, management and outcomes of late biliary complications

\begin{tabular}{|c|c|c|c|c|c|c|c|c|c|c|}
\hline $\begin{array}{l}\text { Case } \\
\text { no. }\end{array}$ & Sex & $\begin{array}{l}\text { Age } \\
\text { (years) }\end{array}$ & $\begin{array}{l}\text { Method of } \\
\text { anastomosis }\end{array}$ & $\begin{array}{l}\text { Underlying } \\
\text { disease }\end{array}$ & Complication & Location & $\begin{array}{l}\text { Length of } \\
\text { stenotic } \\
\text { segment }(\mathrm{mm})\end{array}$ & $\begin{array}{l}\text { Initial } \\
\text { manifestation } \\
\text { (days) }\end{array}$ & Management & $\begin{array}{l}\text { Intervention-free } \\
\text { follow-up interval } \\
\text { (months) }\end{array}$ \\
\hline 1 & $\mathrm{M}$ & 52 & DD & $\mathrm{LC}$ & Stricture & AN & 10 & 219 & PTBD, balloon dilatation (1) & 29 \\
\hline 2 & $\mathrm{M}$ & 58 & DD & $\mathrm{LC}$ & Stricture & AN & 10 & 135 & PTBD, balloon dilatation (1) & 28 \\
\hline 3 & M & 54 & DD & $\mathrm{LC}$ & Stricture & AN & Complete & 211 & PTBD, reoperation & 30 \\
\hline 4 & M & 48 & $\mathrm{HJ}$ & $\mathrm{LC}$ & Stricture & AN & 7 & 22 & $\begin{array}{l}\text { PTBD, balloon dilatation (5), } \\
\text { reoperation }\end{array}$ & 56 \\
\hline 5 & $\mathrm{M}$ & 5 & $\mathrm{HJ}$ & BA & Stricture & AN & Complete & 716 & PTBD, reoperation & 50 \\
\hline 6 & $\mathrm{M}$ & 43 & DD & $\mathrm{LC}$ & Stricture & AN & 15 & 218 & PTBD, balloon dilatation (1) & 31 \\
\hline 7 & $\mathrm{~F}$ & 48 & DD & $\mathrm{HCC}$ & Stricture & AN & Complete & 155 & PTBD, reoperation & 39 \\
\hline 8 & $\mathrm{M}$ & 47 & DD & $\mathrm{LC}$ & Leak & T-tube site & & 200 & ERBD & 16 \\
\hline 9 & $\mathrm{~F}$ & 45 & $\mathrm{DD}$ & $\mathrm{HCC}$ & Leak & T-tube site & & 99 & PCD, ERBD & 38 \\
\hline 10 & $\mathrm{M}$ & 51 & DD & $\mathrm{LC}$ & Leak & T-tube site & & 279 & PCD & 10 \\
\hline 11 & $\mathrm{M}$ & 39 & DD & $\mathrm{LC}$ & Leak & T-tube site & & 210 & PCD, ERBD & 37 \\
\hline
\end{tabular}

DD, duct-to-duct; HJ, hepaticojejunal anastomosis; HCC, hepatocellular carcinoma; LC, liver cirrhosis; BA, biliary atresia; AN, anastomotic site; ( ): number of balloon dilatations; PTBD, percutaneous transhepatic biliary drainage; PCD, percutaneous drainage; ERBD, endoscopic retrograde biliary drainage; ENBD, endoscopic nasobiliary drainage

procedure and underwent additional reoperation. Surgical findings and a pathologic examination revealed an inflammatory polyp at the site of stricture that was not detected by preoperative cholangiography (Fig. 6). Two of 3 patients treated with PTBD and revision operation showed an improvement in laboratory findings and image findings and the surgical treatment played curative role. However, in one patient the stricture recurred after the surgical revision. Additional percutaneous external biliary drainage by placing the tube across resolved the problem. Mean catheter dwelling period was 117 days (range 15-180 days).

A late biliary leak developed in 4 patients between days 99 and 279, and showed fluid collection near the T-tube entry site. Mean follow-up period was 25.7 months (range 16-38 months). Endoscopic retrograde cholangiography (ERC) showed a contrast leak at the T-tube insertion site (Fig. 7).

Three patients were treated by PCD with or without ERBD. In 2 of 3 patients treated by ERBD, PCD was also performed because of a sizeable fluid collection in the peritoneal cavity. In 1 patient, PCD was the only treatment. Mean catheter dwelling period was 26 days (range 4-60 days).

\section{Complications of Percutaneous and Endoscopic Procedures}

In 1 patient with an early biliary leak and stricture, osteomyelitis of the rib developed near the PTBD insertion site. The PTBD tube near the infected focus was removed and a new tube was inserted. Osteomyelitis and biliary complications were successfully managed conservatively. In another patient with a late biliary leak, a duodenal perforation occurred as a complication of ERBD. The biliary leak was managed by PCD and the symptoms of duodenal perforation improved with conservative treatment. Clogging of the PTBD tube by bile sludge and debris required repeated PTBD tube changes in 1 patient with late biliary stricture. Retraction of the PTBD tube was another main cause of tube change in 5 patients.

\section{Discussion}

In previous studies concerning the complications of liver transplantation [1, 8-13], biliary complications have been reported in $15-64 \%$ of cases. The current standard for biliary reconstruction in reduced size graft liver transplantations such as LDLT, the preferred technique is the Roux-en-Y hepaticojejunostomy, whereas in cadaveric liver transplantations it is direct duct-to-duct choledochocholedochostomy. Choledochocholedochostomy biliary reconstruction is known to preserve the normal physiologic sphincter mechanism and prevent reflux cholangitis. In addition, it allows access for radiologic evaluation of the biliary tract by endoscopic retrograde cholangiopancreatography (ERCP). The reason for using the Roux-en-Y hepaticojejunostomy for reduced-size grafts is the small size of the recipient bile duct and the inadequate length of the donor bile duct [14].

Biliary leak and/or stricture result in a deterioration of liver function, abscess, and even sepsis if an appropriate procedure for biliary diversion is not provided at an early stage [4]. Furthermore, early recognition and appropriate management of biliary complications greatly affect graft and patient survival [5]. Alterations in liver function tests are not accurate indicators of biliary complications, and a differential diagnosis of biliary obstruction or chronic rejection cannot be assessed without the help of imaging investigations including US, CT, MRI, and cholangiography [15]. Therefore, knowledge of the imaging spectrum of biliary complications in LDLT, and of appropriate interventional procedures for the treatment of biliary complications, is mandatory.

In this study, the incidence of biliary complications was $16.4 \%$, which is in good agreement with other reports [813]. Important factors that contribute to the development of biliary complications in LDLT include a small-sized bile duct and anatomic complexity of the right duct, which result in anastomosis of more than one branch to the bowel [3]. Meticulous dissection adjacent to the duct is another factor 

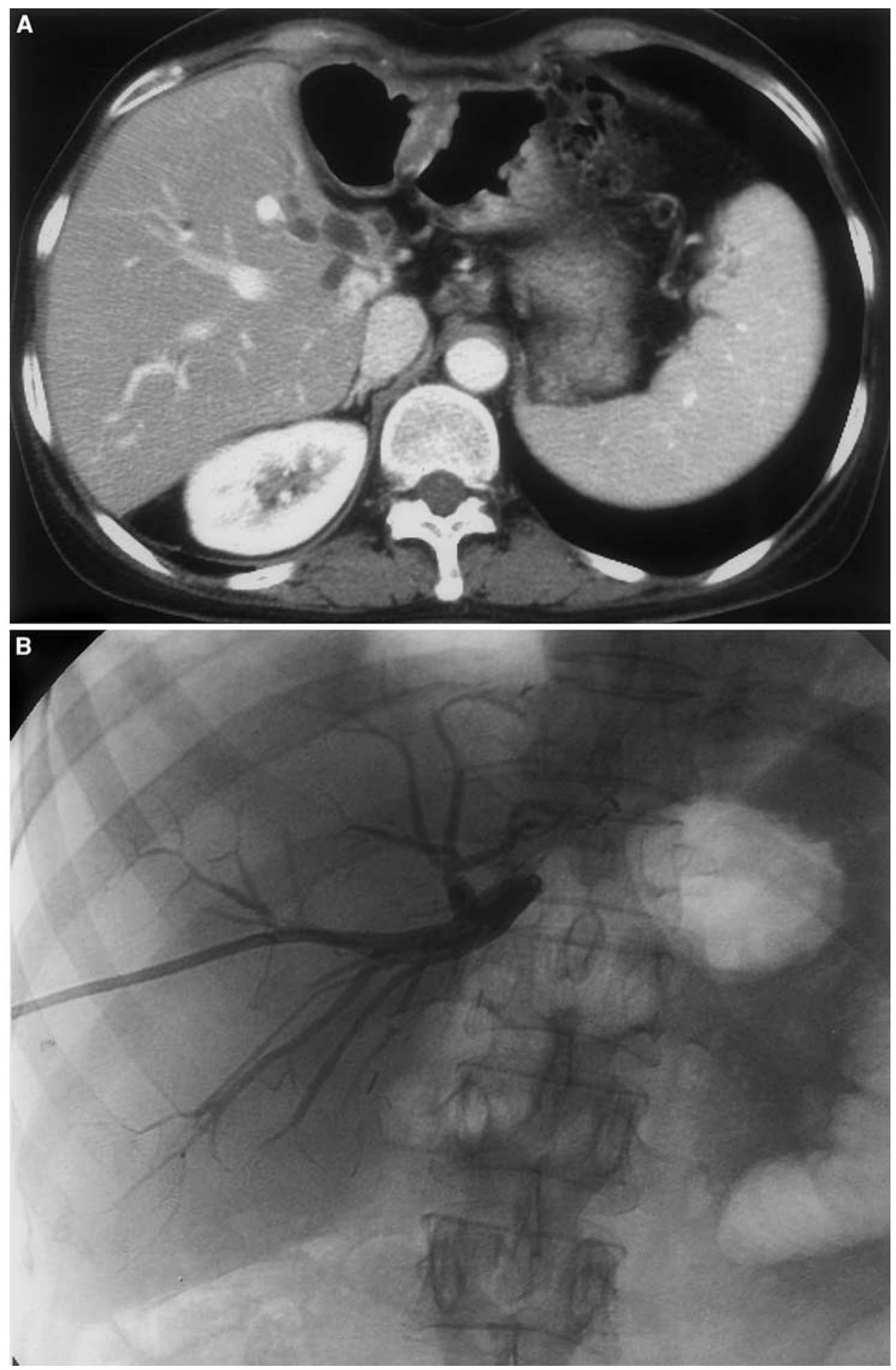

Fig. 5. A,B. A 48-year-old woman 517 days after right lobe LDLT. A Contrast-enhanced CT scan shows intrahepatic duct dilatation. B Cholangiogram obtained by PTBD shows complete occlusion of the biliary duct at the anastomotic site. A revision operation was performed with choledochojejunostomy.

that contributes to early edema resulting in early leakage and stricture at the anastomotic site [1].

Based on previous studies including LDLT [5], the median time interval between onset of biliary stricture and liver transplantation was 5.9 months and between bile leak and liver transplantation was 0.7 month. Similarly, according to studies of orthotopic liver transplantation, most bili- ary complications become evident within 3 months. In addition, if late complications occur (from a few months to several years after transplantation), they are usually stricture. Bile leaks are generally an early complication after liver transplantation, and in $70 \%$ of cases were found within 1 month [16, 17]. Early leaks may originate from the anastomotic site, the cystic duct stump, and the cut surface 


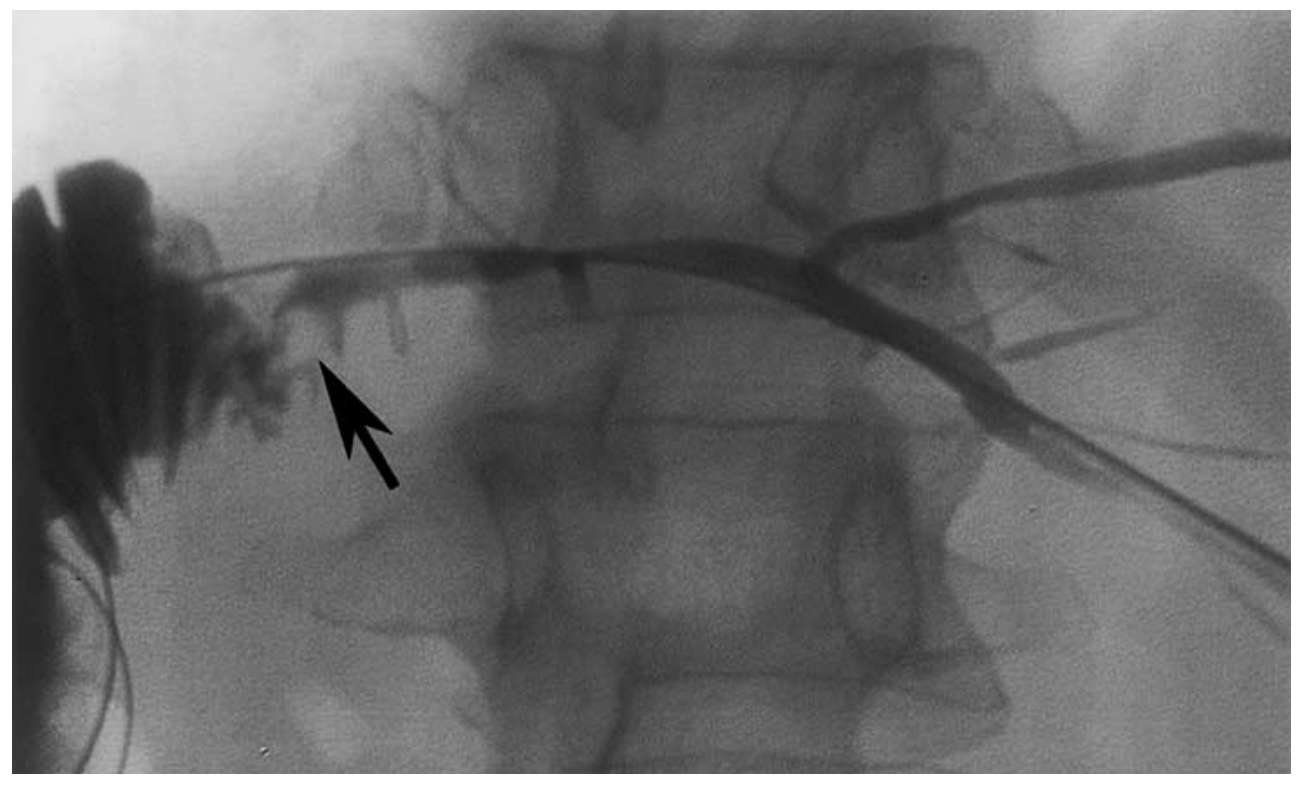

Fig. 6. A 48-year-old man with left lobe LDLT developed late complication 225 days after liver transplantation. Cholangiogram shows a round filling defect at the choledochojejunostomy anastomotic site (arrow), which was later confirmed as an inflammatory polyp by laparotomy. of the liver. However, in our study, biliary leak and stricture occurred during both the early and late periods after LDLT. Furthermore, $46 \%(6 / 13)$ of late complications were bile leak. The difference in types of complications between our study and others may be attributable to the fact that T-tuberelated bile leak was included as a late biliary leak. Furthermore, differences in surgical techniques or experience, different patient populations, and a previous history of transarterial chemoembolization before LDLT could be possible causes.

There is some debate regarding the appropriate treatment for biliary leak. In past, some authors [18] have stated that any demonstration of a bile leak should be managed by prompt surgical repair unless the leak is so small that simple drainage of the duct can be expected to resolve the situation. The basic theoretical background for surgical treatment is that leaks at the anastomotic site are primarily caused by ischemic necrosis of the bile duct or by a technically unsatisfactory anastomosis [4]. By the same token, one series reported that more than half of anastomotic leaks are associated with hepatic artery thrombosis [19]. However, others have reported that only $14 \%$ of patients with biliary leaks require operative repair in orthotopic liver transplantation [20]. In addition, only 1 of 9 bile leaks needed surgical treatment in other report on LDLT [5]. In our cases of early leak only 1 patient showed arterial compromise, which resulted in severe bile duct necrosis. However, in most cases there was no evidence of arterial compromise, and biliary leaks were well controlled by interventional procedures. Only in 1 patient, who showed total dehiscence of the anastomosis, was surgical revision necessary. Therefore, we believe that bile leak can be primarily managed by interventional methods unless there is an evidence of hepatic artery stenosis, such as multifocal ductal stricture or necrosis.
In our study, an early biliary leak was associated with biliary stricture in 5 patients $(5 / 24,21 \%)$. Ametani et al. [21] reported that a bile leak induces fibrosis at the anastomotic site. In one of our cases the first manifestation of bile duct narrowing with bile leak was noted at 8 days after operation. In this case, the cause of bile duct narrowing might have been edema or a tight suture. Since the incidence of biliary leak accompanied by stricture is relatively high, simple drainage of biloma may not be enough. PTBD and biliary diversion are also necessary not only to evaluate the biliary anatomy and possible stricture but also to promote healing and shorten the duration of hospitalization. In addition, PTBD provides an access route for balloon dilatation of the stricture. ERBD could be an alternative option, but given that direct drainage of biloma will reduce the treatment duration, combined PCD with PTBD is seemingly the better option.

Strictures that developed during the first few weeks were primarily at the anastomotic site, and secondary to local ischemia or a suturing technique that produced excessive narrowing. Non-anastomotic-site strictures probably have ischemic, infectious, or immunologic causes [22, 23]. Based on previous reports, intervention produces good long-term results in most cases with an anastomotic site stricture [5, 24]; non-anastomotic strictures, presumably related to bile duct ischemia, showed poor results [25]. The same rule applies to LDLT patients.

When biliary problems first manifest at more than 6 months after transplantation, strictures and obstruction dominate the clinical picture. Late biliary stricture could be classified as anastomotic, hilar, or intrahepatic, and have variable causes such as hepatic artery occlusion, preservation injury, rejection, and recurrent disease [4]. Management of late complications is largely influenced by the nature and extent of strictures. In our study, all late biliary strictures 

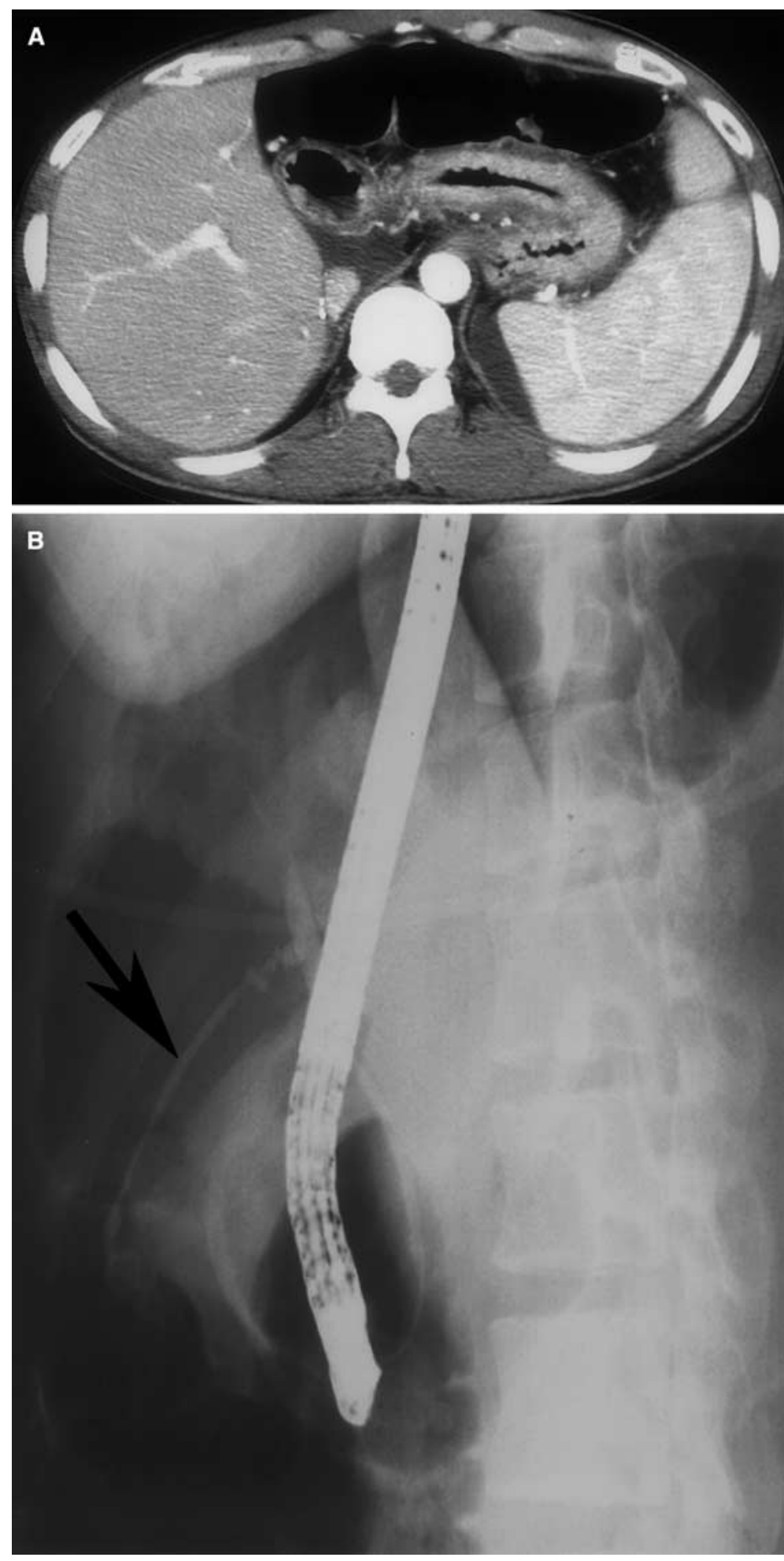

Fig. 7. A,B. A 39-year-old man with right lobe LDLT developed a bile leak after T-tube removal.

A Contrast-enhanced abdominal CT scan shows a small fluid collection was noted at the edge of the transplant graft. B Cholangiogram obtained by ERCP 4 days after $\mathrm{T}$-tube removal shows contrast material along the T-tube tract (arrow).

$(7 / 24,29 \%)$ were noted at the anastomotic site and there was no evidence of arterial compromise or other significant cause. In 4 patients with late biliary strictures $(4 / 7,57 \%)$ reoperation was necessary. In 3 of these patients a guidewire would not pass the stricture focus. Two showed complete obstruction. In 1 case the downward bile passage was faintly visualized, but we failed to pass the guidewire though the stenotic portion (Fig. 8). A more meticulous technique was necessary to pass the stricture site, because if we could have passed the stenotic portion reoperation could have been avoided. These 3 cases were confirmed to be due to massive fibrosis. In another case, passage of the guidewire was possible but repeated balloon dilatation failed to resolve the stricture. A reoperation was performed and pathology was 


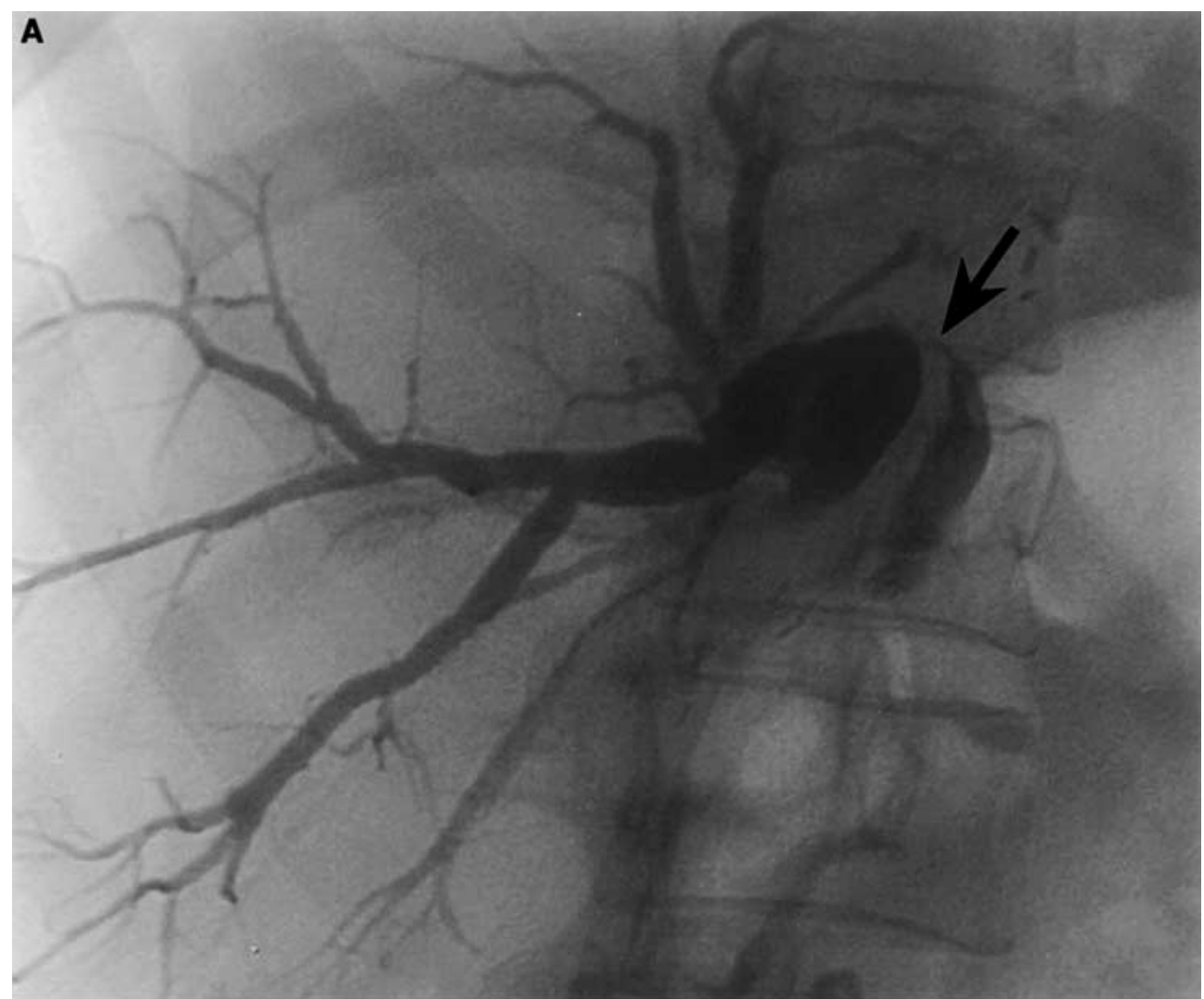

B

Fig. 8. A,B. A 48-year-old woman with right lobe LDLT developed a biliary stricture 517 days postoperatively. A Cholangiogram obtained after guidewire placement through the bile duct. Stricture is noted at the anastomotic site (arrow). B PTBD (arrow) was inserted just distal to the stenotic portion (arrowhead).

Downstream flow is faintly visualized. We failed to traverse the stricture site and a reoperation was necessary.

confirmed to be an inflammatory polyp, which was not detected by cholangiography before reoperation. However, a retrospective review of the cholangiogram revealed a round filling defect at the anastomotic site. Therefore, careful evaluation of the cholangiogram is important to avoid unnecessary intervention.

In our study all late biliary leaks $(4 / 24,17 \%)$ were associated with the T-tube removal. Most T-tube-related 
bile leaks probably result from peritoneal spillage of bile, because of poor T-tube tract formation and a dysfunctional ampulla of Vater after liver transplantation [5, 16, 18]. Ttube-related leaks are often small and most patients have no symptoms. Occasionally, however, biliary leaks can cause biloma or bile peritonitis, which need radiologic or surgical intervention [17]. Endoscopic sphincterotomy with biliary stent or catheter insertion was effective [19, 24].

In patients with choledochocholedochal reconstruction, ERCP should be performed initially, and in patients with choledochoenteric anastomosis, PTBD should be the procedure of choice [4]. At our institute, however, PTBD or PCD is sometimes used as a first choice even in patients with choledochocholedochal anastomosis. This is because the percutaneous procedure has very low complication rate in our institute and catheter management and follow-up is easier with a percutaneous technique. Furthermore, this modality played a primary role in 4 cases in which endoscopic procedures were insufficient or caused a serious complication, such as bowel perforation.

Our study has two limitations. The first is that it is retrospective and second is that the follow-up period may have been insufficient to determine the outcome of the interventional procedures. Therefore, a longer period of study is probably necessary.

In conclusion, biliary complications in LDLT are relatively common and biliary leaks and strictures predominate. Even though nonsurgical approaches may require repeated radiologic examinations and interventions, good results can be obtained in most biliary complications not associated with arterial compromise. However, cases of complete biliary obstruction show a poor response to radiologic intervention alone.

\section{References}

1. Fulcher AS, Turner MA, Ham JM (2002) Late biliary complications in right lobe living donor transplantation recipients: Imaging findings and therapeutic interventions. J Comput Assist Tomogr 26:422-427

2. Ghobrial RM, Saab S, Lassman C, et al. (2002) Donor and recipient outcomes in right lobe adult living donor liver transplantation. Liver Transplant 8:901-909

3. Marcos A, Fisher RA, Ham JH, et al. (1999) Right lobe living donor liver transplantation. Transplantation 66:798-803

4. Moser MAJ, Wall WJ (2001) Management of biliary problems after liver transplantation. Liver Transplant 7:S46-S52

5. Park JS, Kim MH, Lee SK, et al. (2003) Efficacy of endoscopic and percutaneous treatments for biliary complications after cadaveric and living donor liver transplantation. Gastrointest Endosc 57:78-85

6. Schwarzenberg SJ, Sharp HL, Payne WD, et al. (2002) Biliary stricture in living-related donor liver transplantation: Management with balloon dilation. Pediatr Transplant 6:132-5
7. Sawada S, Tanigawa N (1999) Percutaneous transhepatic biliary drainage. In: Han MC, Park JH, (eds). Interventional radiology 1st edn. Seoul, Ilchokak, pp 540-552

8. Inomata Y, Uemoto S, Asonuma K, et al. (2000) Right lobe graft in living donor liver transplantation. Transplantation 69:258-264

9. Marcos A, Ham JM, Fisher RA, et al. (2000) Single-center analysis of the first 40 adult-to-adult living donor liver transplants using the right lobe. Liver Transplant 6:296-301

10. Miller CM, Gondolesi GE, Florman S, et al. (2001) One hundred nine living donor liver transplants in adults and children: A single center experience. Ann Surg 234:301-312

11. Testa G, Malago M, Valentin-Gamazo C, et al. (2000) Biliary anastomosis in living related liver transplantation using the right lobe: Techniques and complications. Liver Transplant 6:710-714

12. Bak T, Wachs M, Trotter J, et al. (2001) Adult-to-adult living donor liver transplantation using the right lobe grafts: Results and lessons learned from a single-center experience. Liver Transplant 7:680-686

13. Grewal HP, Shokouh-Amiri MH, Vera S, et al. (2001) Surgical technique for right lobe adult living donor liver transplantation without venous bypass or portocaval shunting and with duct-to-duct biliary reconstruction. Ann Surg 233:50-508

14. Kawachi S, Shimazu M, Wakabayashi G, et al. (2002) Biliary complications in adult living donor liver transplantation with duct-to-duct hepaticocholedochostomy or Roux-en-Y hepaticojejunostomy biliary reconstruction. Surgery 132:48-56

15. Laghi A, Pavone P, Catalano C, et al. (1999) MR cholangiography of late biliary complications after liver transplantation. AJR Am J Roentgenol 172:1541-1546

16. Greif F, Bronsther OL, Van Thieil DH, et al. (1994) The incidence, timing and management of biliary tract complications after orthotopic liver transplantation. Ann Surg 219:40-45

17. Sheng R, Sammon JK, Zajko AB, Campbell WL (1994) Bile leak after hepatic transplantation: Cholangiographic features, prevalence, and clinical outcome. Radiology 192:413-416

18. Shaw BW (1986) Surgical and clinical aspects of liver transplantation and postoperative evaluation of complications. Semin Intervent Radiol 3:115-119

19. Ward EM, Wiesner RH, Hughes RW, Krom RAF (1991) Persistent bile leak after liver transplantation: Biloma drainage and endoscopic retrograde cholangiopancreatographic sphincterotomy. Radiology 179:719-720

20. Osorio RW, Freise CE, Stock PG, et al. (1993) Nonoperative management of biliary leaks after orthotopic liver transplantation. Transplantation 55:1074-1077

21. Ametani F, Itoh K, Shibata T, et al. (2001) Spectrum of CT Findings in pediatric patients after partial liver transplantation. Radiographics 21:53-63

22. Lorenz JM, Funaki B, Leef JA, Rosenblum JD, Ha TV (2001) Percutaneous transhepatic cholangiography and biliary drainage in pediatric liver transplant patients. AJR Am J Roentgenol 176:761-765

23. Mosca S, Militerno G, Guardascione MA, et al. (2000) Late biliary tract complications after orthotopic liver transplantation: Diagnostic and therapeutic role of endoscopic retrograde cholangiopancreatography. J Gastroenterol Hepatol 15:654-660

24. Ostroff JW, Roberts JP, Gorden RL, Ring EJ, Ascher NL (1990) The treatment of $\mathrm{T}$ tube leaks in orthotopic liver transplant recipients with endoscopically placed nasobiliary catheters. Transplantation 49:922924

25. Rerknimitr R, Sheurman S, Fogel EL, et al. (2002) Biliary tract complications after orthotopic liver transplantation with choledochocholedochostomy anastomosis: Endoscopic findings and results of therapy. Gastrointest Endosc 55:224-231 